\title{
Analysis of arterial blood gases in the curarized, artificially respirated rat $^{1}$
}

\author{
LEO V. DiCARA, THE ROCKEFELLER \\ UNIVERSITY, New York, New York \\ 10021
}

The present paper describes a simple and accurate technique for the artificial respiration of curarized rats that avoids the trauma involved in a tracheotomy. Success of the technique depends on the proper positioning of a special face mask on the rat. The results of an experiment on arterial blood gases in 48 curarized rats are presented to illustrate the accuracy and effectiveness of the techniques described.

This paper reports a simple technique for the artificial respiration of curarized rats by means of a face mask and a relatively inexpensive small-animal respirator. The techniques described have been used in previous experiments in this laboratory on the instrumental conditioning of visceral and glandular responses (DiCara \& Miller, 1968a, b, c, d; Miller \& DiCara, 1967, 1968). The results of an experiment on arterial blood gases are presented to illustrate the accuracy and effectiveness of the techniques described.

\section{Subjects}

\section{METHOD}

$A$ total of 48 male albino Sprague-Dawley rats were used in two experiments. Rats were divided into two groups on the basis of body weight. There were 24 rats with a mean body weight of $503 \pm 12.7 \mathrm{~g}$ in the first group and 24 rats with a mean body weight of $401 \pm 10.4 \mathrm{~g}$ in the second.

\section{Catheter Implantation}

Each rat was anesthetized with $40 \mathrm{mg} / \mathrm{kg}$ Nembutal, and a catheter consisting of polyethylene tubing connected to a length of Vivosil tubing (i.d. 012, o.d. 025) was implanted into the lower third of the abdominal aorta; the distal end was threaded under the skin and brought out at the back of the neck (DiCara \& Miller, 1968d). The catheter was filled with Ringer's solution and heat-sealed. Rats were allowed 1 week to recover from the operation.

Fig. 1. Apparatus and face mask used to hold and artificially respirate a curarized rat.

\section{Precurarization Procedures}

A $0.25-\mathrm{ml}$ sample of blood from the aortic catheter was obtained from each rat prior to curarization. The collection of blood was carried out under anaerobic conditions in a heparinized gas-tight syringe. Analysis of blood gases was carried out immediately, using a micro-pH and gas-analyzing system (Instrumentation Laboratory, Inc., Model 113-S2). This apparatus enables the operator to determine, with a minute volume of blood, $\mathrm{P}_{\mathrm{CO}_{2}}$ determination to within $\pm 0.5 \mathrm{~mm} \mathrm{Hg}$ and $\mathrm{PO}_{2}$ determination to within $\pm 1.0 \mathrm{~mm}$ $\mathrm{Hg}$. The blood-gas analyzing system was calibrated daily by means of analyzed gas mixtures. Analyses of blood gases were carried out at $37^{\circ} \mathrm{C}$ and have been corrected for an $\mathrm{O}_{2}$ membrane factor and ambient barometric pressure.

Curarization and Procedures for Artificial Respiration

The rats were injected intraperitoneally with $2 \mathrm{mg} / \mathrm{kg}$ of d-tubocurarine chloride (Squibb) in a solution containing $3 \mathrm{mg} / \mathrm{ml}$. As soon as the rat showed the first signs of difficulty in breathing, it was fitted with a specially constructed, airtight face mask.
The mask is made from the mouthpiece end of a rubber balloon placed over a plastic tube $(3.0-\mathrm{cm}$ diam). The rat's snout is placed in this plastic tube, and the lower lip of the mouthpiece end of the balloon is hooked behind the upper incisors. The rat's head is held in place by adjustable bars placed behind it on the occipital ridge, as shown in Fig. 1. The upper portion of the balloon is held in place on the dorsal surface of the rat's snout by elastic pressure; the fit is airtight. In extreme tests, we have respirated curarized rats under water for over $15 \mathrm{~min}$ without detecting any air bubbles. The end of the plastic tube, over which the balloon is placed, is connected via a rubber stopper, with a hole drilled through its middle to a small-animal artificial respirator equipped with solenoid valves to prevent rebreathing of expired air (ENM Instrument Co., Model VE5AG). The total dead air-space volume between the pump and the rat is $8.3 \mathrm{cc}$.

Previous experiments have demonstrated that if rats are artificially respirated at 1-to-1 I/E ratio, 70 breaths/min, and a peak inspiration pressure of $20 \mathrm{~cm} \mathrm{H}_{2} \mathrm{O}$, they maintain normal heart rate,

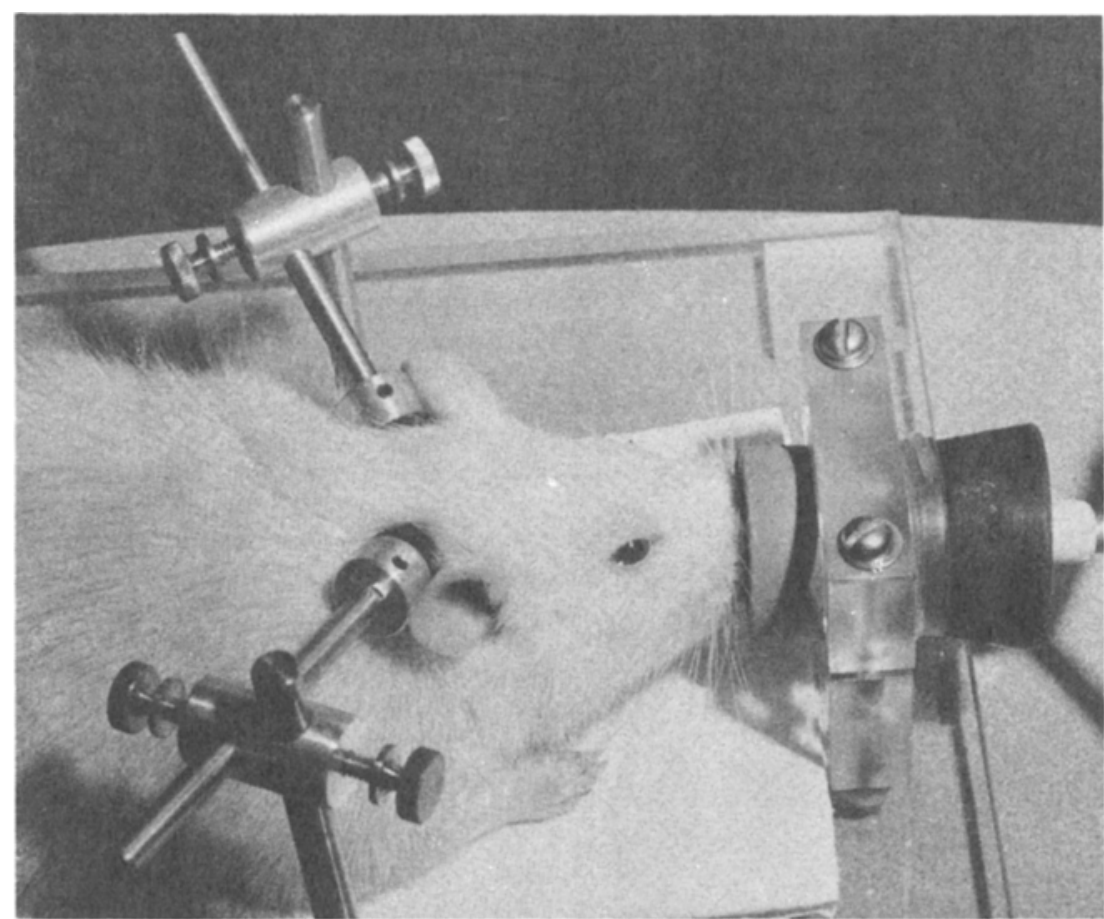




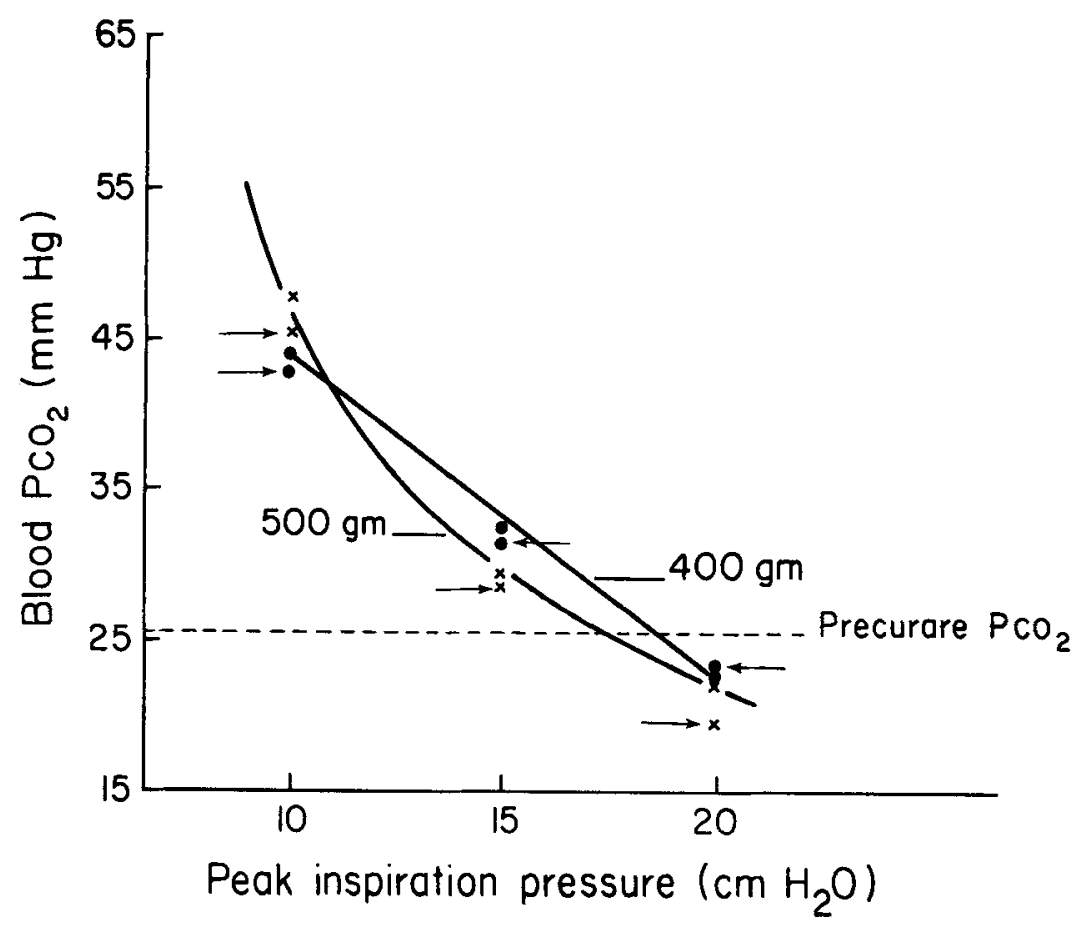

temperature, and peripheral vasomotor responses. In order to obtain more extensive information about the relationship between arterial blood gas composition and artificial respiration in curarized rats, each rat in the present experiment was respirated for $60 \mathrm{~min}$ at each of three different levels of peak inspiration pressure: 10,15 , and $20 \mathrm{~cm}$ $\mathrm{H}_{2} \mathrm{O}$. Inspiration/expiration ratio and rate were held constant at a 1-to-1 ratio and 70 cycles/min for all rats. The peak inspiration
Fig. 2. Arterial $\mathrm{PcO}_{2}$ as a function of peak inspiration pressure at a 1-to-1 $1 / \mathrm{E}$ ratio and 70 cycles/min.

and a 1-to-1 ratio. As the animal was respirated, the pressure in the plethysmograph varied directly with the volume of tidal air. The pressure changes of the system were transmitted to a Statham pressure transducer and were amplified by a Grass polygraph (Model 5). In order to calibrate the system, the rat respirated was killed by asphyxiation after an injection of Nembutal and an airtight syringe connected to this system, and the pen deflection produced by moving known volumes of air in and out at 70 cycles/min was recorded. Under these conditions, the gas compression was approximately adiabatic.

\section{RESULTS}

The main results are presented in Figs. 2 and 3. In Fig. 2, arterial blood $\mathrm{PcO}_{2}$ is shown as a function of peak inspiration pressure. Values of arterial blood $\mathrm{PcO}_{2}$ measured before curarization and after $1 \mathrm{~h}$ of artificial respiration are shown for the two groups of rats. Fig. 3 presents similar measurement of arterial $\mathrm{Po}_{2}$. The points marked by arrows in both figures represent the mean arterial blood gas obtained during the second and third hours of artificial respiration. The close agreement between each set of points indicates that the sequence in which the peak inspiration pressure was changed during curarization did not have any systematic effect on level of arterial blood $\mathrm{PcO}_{2}$ or $\mathrm{Po}_{2}$. This was confirmed by a statistical analysis of variance.

As can be seen from Figs. 2 and 3 , normal noncurarized rats have an arterial blood $\mathrm{PCO}_{2}$ of $25.4 \mathrm{~mm} \mathrm{Hg}$ and an arterial blood $\mathrm{Po}_{2}$ of $75.1 \mathrm{~mm} \mathrm{Hg}$. Although the $\mathrm{Po}_{2}$ levels are below the normal range for man, they are quite normal for rats, as are the $\mathrm{PCO}_{2}$ values (Jones, MacGrath, \& Aculthorpe, 1950; King \& Bell, 1966). Normal arterial blood $\mathrm{PCO}_{2}$ and $\mathrm{PO}_{2}$ can be maintained in curarized rats by artificial respiration at a peak inspiration pressure of approximately $17-19 \mathrm{~cm} \mathrm{H}_{2} \mathrm{O}$ at a rate of 70 beats/min and a 1-to-1 $\mathrm{I} / \mathrm{E}$ ratio.

Figure 4 illustrates the relationship between peak inspiration pressure and tidal volume in rats of different body weights. Each point on the curves represents the mean of 36 observations obtained on six

Fig. 3. Arterial blood $\mathrm{Po}_{2}$ as a function of peak inspiration pressure at a 1-to-1 I/E ratio and $70 \mathrm{cycles} / \mathrm{min}$. 


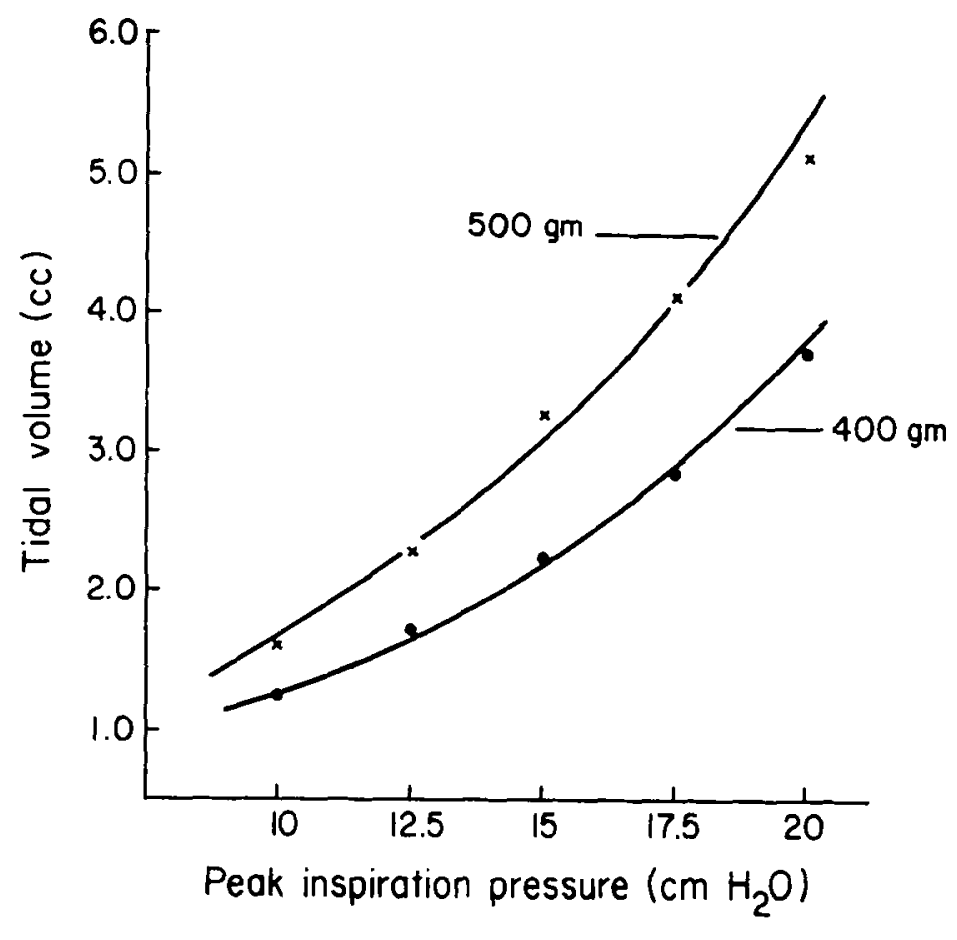

rats. There is a linear relationship between pressure and tidal volume, and, as expected, heavier rats showed a higher tidal volume at a given peak pressure.

\section{DISCUSSION}

In addition to confirming the results of previous experiments on blood-gas composition in the normal rat (King \& Bell, 1966), the present experiment describes a simple and accurate technique for the artificial respiration of curarized rats. The technique avoids the surgical trauma involved in a tracheotomy. Success of the technique depends on the proper positioning of the face mask. For instance, the rat should be artificially ventilated as soon as it shows the initial effects of curarization and held in place in the mask, with the head extended, by hand if necessary, until total paralysis is achieved. This will minimize the possibility of bronchoconstriction, laryngospasm, obstruction of the glottis, and subsequent passage of air into the rat's stomach.

\section{REFERENCES}

DiCARA, L. V., \& MILLER, N. E. Changes in
Fig. 4. Peak inspiration pressure and tidal volume in curarized rats of different body weights.

heart rate instrumentally learned by curarized rats as avoidance responses. Journal of Comparative \& Physiological Psychology, 1968a, 65, 8-12.

DiCARA, L. V., \& MILLER, N. E. Instrumental learning of peripheral vasomotor responses by the cararized rat. Communications in Behavioral Biology, Part A, 1968b, 1, 209-212.

DiCARA, L. V., \& MILLER, N. E. Instrumental learning of vasomotor responses by rats: Learning to respond differentially in the two ears. Science, 1968c, 159, 1485-146.

DiCARA, L. V., \& MILLER, N. E. Instrumental leaming of systolic blood pressure by curarized rats: Dissociation of cardiac and vascular changes. Psychosomatic Medicine, 1968d, 30, 489-494.

JONES, S. E., MacGRATH, B. C., \& ACULTHORPE, H. H. Pathological processes in disease: II. Blood of the albino rat. Approximate physico-chemical description. Annals of Tropical Medicine \& Parasitology, 1950, 44, 168-186.

KING, T. K. C., \& BELL, D. Arterial blood gases in specific pathogen free and bronchitic rats. Journal of Applied Physiology, 1966, 21, 237-241.

MILLER, N. E., \& DiCARA, L. V. Instrumental learning of heart-rate changes in curarized rats: Shaping, and specificity to discriminative stimulus. Journal of Comparative \& Physiological Psychology, 1967, 63, 12-19.

MILLER, N. E., \& DiCARA, L. V. Instrumental learning of urine formation by rats; changes in renal blood flow. American Joumal of Physiology, 1968, 215, 677-683.

NoTE

1. The research was supported by PHS Grants MH 16569 and MH 13189, by a research grant, 69-797, from the American Heart Association. and by a Career Development Award, GM-34,110. 